\title{
The Dawning of a New Sedative: Propofol in Gastrointestinal Endoscopy
}

\author{
Ludwig T. Heuss ${ }^{a}$ Werner Inauen ${ }^{b}$ \\ aDepartment of Gastroenterology, University Hospital, Basel, and b Gastroenterology Center, Bürgerspital, \\ Solothurn, Switzerland
}

\section{Key Words}

Propofol · Nurse-administered sedation .

Patient-administered sedation

\begin{abstract}
Background: Using gentler endoscopes and improved sedation, great strides have been made in enhancing patients' comfort and acceptance of endoscopic procedures. Because morbidity and mortality have been associated with benzodiazepines in endoscopic sedation, safer alternatives were sought. Propofol (2,6-diisopropylphenol), a rapid and short-acting anesthetic, initially used in the 1980's for general anesthesia induction and maintenance, is a promising candidate. Methods: This review article examines experiences and literature references of propofol's use in endoscopic procedures. Three critical questions are posed: What are the major advantages and potential risks of propofol? When should propofol be used? Who should administer propofol, how should it be administered, and what type of monitoring is required? Results: With considerable inter-patient variability, the propofol dose must be carefully titrated according to the individual patient's response. Factors influencing dosage include age, ASA class, patient's height and procedure duration. Propofol's primary risk is its narrow therapeutic range which necessitates careful
\end{abstract}

\section{KARGER}

Fax +4161306 1234

E-Mail karger@karger.ch

www. karger.com
(C) 2004 S. Karger AG, Basel

0012-2823/04/0691-0020\$21.00/0

Accessible online at:

www. karger.com/dig patient monitoring. Conclusions: Propofol's advantages over benzodiazepines and narcotics include a more rapid onset of action, full relief of discomfort and rapid recovery to alertness without residual sedative effects or anterograde amnesia, thereby making this drug a cost-effective and, with proper monitoring, safe choice.

Copyright $@ 2004$ S. Karger AG, Basel

\section{Introduction}

\section{Role of Sedation for Endoscopy}

The development of flexible fiberoptic endoscopes was a considerable step forward in the direct visual investigation of the body's interior without compromising its integrity. Nevertheless, for most patients, endoscopy remained an unpleasant experience that launched two major directions of further clinical developments: (1) The invention of smaller, smoother and more sophisticated instruments that enhance the procedure's tolerability [1], and (2) the introduction of, and improvement in, conscious sedation. Both developments are strongly correlated with the expanding frontiers of newer interventional techniques [2].

Although many clinical trials have documented the feasibility of endoscopies without any sedation [3-5], and reduction of cardiac stress under sedation does not seem to be a strong argument $[6,7]$, given the choice, a majority 
of patients would undoubtedly prefer sedation [8]. Patients' opinions probably depend not solely on their own personal experiences: the (poor) reputation of endoscopic procedures and patients' fears have become a consideration in public health viz. the predicted need for screening colonoscopies [9]. Finally, sedation should not be judged solely from the patient's perspective (i.e. making endoscopies more comfortable for patients), but also as a way of facilitating the procedure for the endoscopist, the latter being of increasing importance the more difficult the intervention [10].

\section{Sedation with Benzodiazepines as Routine Practice}

Several tragic deaths occurred when benzodiazepines were first being used. Nevertheless, since the 1980s, the use of benzodiazepines, often in combination with an analgesic, has become standard practice in the United States and many parts of Europe [11, 12]. However, even in the $1990 \mathrm{~s}$, a remarkable morbidity $(1: 200$ to $1: 2,000)$ and occasional mortality were still being reported with its use $[13,14]$.

\section{Propofol}

Besides the benzodiazepines, interest in another substance for endoscopic sedation has increased during the past few years: propofol [15]. With growing evidence supporting its use in both adults and children [16-23] propofol now stands at the threshold of a broad introduction into the endoscopy suite. Today, three major questions regarding its use have to be answered:

- What are the major advantages, and potential risks, of propofol?

- When should propofol be used?

- Who should administer propofol and how?

\section{Advantages and Potential Risks of the Drug}

\section{Pharmacokinetics}

Propofol (2,6-diisopropylphenol) is a rapid and shortacting anesthetic that came into use in the late 1980s. For quite some time, it was primarily used for the induction and maintenance of general anesthesia [24]. Its high lipid solubility results in a very fast onset of action (30-60 s) [25]. Following an initial bolus of propofol, the effect is terminated by a rapid redistribution of the substance to less well-perfused tissues and prompt hepatic conjugation. Nevertheless, a largely extrahepatic clearance without active metabolites exists making the substance also suitable for patients with liver disease [26]. Accordingly, the plasma half life ( $\mathrm{t}^{1 / 2}$ distribution) is very short with 1.3-4.1 min (compared with $30 \mathrm{~min}$ for midazolam). This results in a rapid decline of propofol concentrations to levels below those required for hypnosis, and permits a rapid awakening even after prolonged administration [24]. The pharmacokinetics of propofol permit it to be given intravenously, either in bolus doses (usually in increments of 10-20 mg, depending on the clinical effect), or by continuous infusion with which different levels of sedation can be easily achieved with a change in dose [22]. The clinical applications of propofol have expanded within the past few years, and now include sedation in intensive care units and for outpatient procedures [27-29]. The exact mechanism of action of the drug is unclear, but, as with other CNS depressants, propofol may act on GABA receptors [24]. Propofol has good amnesic, but only minimal analgesic, properties and is often combined with an analgesic. It does not seem to markedly interfere with gastrointestinal motility [30]. With considerable inter-patient variability, the dosage has to be carefully titrated according to the individual patient's clinical state.

Age is one central determinant of the dosage required, and must be substantially reduced with increasing age [31] (cf. fig. 1). Other independent parameters that influence the dosage include ASA class (cf. table 1), the patient's height and the duration of the procedure [20, 32].

The advantages of propofol compared to benzodiazepines and narcotics are directly related to its properties: a more rapid onset of action, full relief from discomfort and rapid recovery to alertness without residual sedative effects or imponderable anterograde amnesia. As most endoscopy units are coming under increasing financial pressures, economic arguments for improved efficiency, e.g. faster patient discharge or reduction of procedure time, are important factors cited in the rationale for using propofol in routine endoscopy. Propofol patients also report a higher degree of satisfaction compared to benzodiazepine patients [9]. Propofol reduces costs in the recovery room and is associated with a more rapid return of patients to work or leisure [33].

\section{Level of Sedation}

Sedation is a continuum of progressive impairment in consciousness that has been roughly divided into four different levels, ranging from anxiolysis or minimal sedation to general anesthesia [34] (cf. table 2).

Although in the literature, the use of propofol is often associated with deep sedation, it is essential to note that the level of sedation is primarily dose dependent. Deep 
sedation can also be achieved by administration of benzodiazepines, while small doses of propofol can lead solely to anxiolysis without any reduction in vigilance. When used as a single substance, the lacking analgesic effect may possibly lead endoscopists to aim for deeper levels of unconsciousness [9]. Nevertheless, propofol can be used to achieve a state of conscious sedation where communication is still possible.

\section{Risks}

The principal and most important risk of propofol use is its narrow therapeutic range. This poses the danger that

Table 1. ASA classes according to the American Society of Anesthesiologists

\begin{tabular}{ll}
\hline P1 & normal healthy patient \\
P2 & patient with mild systemic disease \\
P3 & patient with severe systemic disease \\
P4 & $\begin{array}{l}\text { patient with severe systemic disease that is a constant threat } \\
\text { to life }\end{array}$ \\
P5 & $\begin{array}{l}\text { moribund patient, not expected to survive without the } \\
\text { operation }\end{array}$
\end{tabular}

Based on the American Society of Anaesthesiologists.

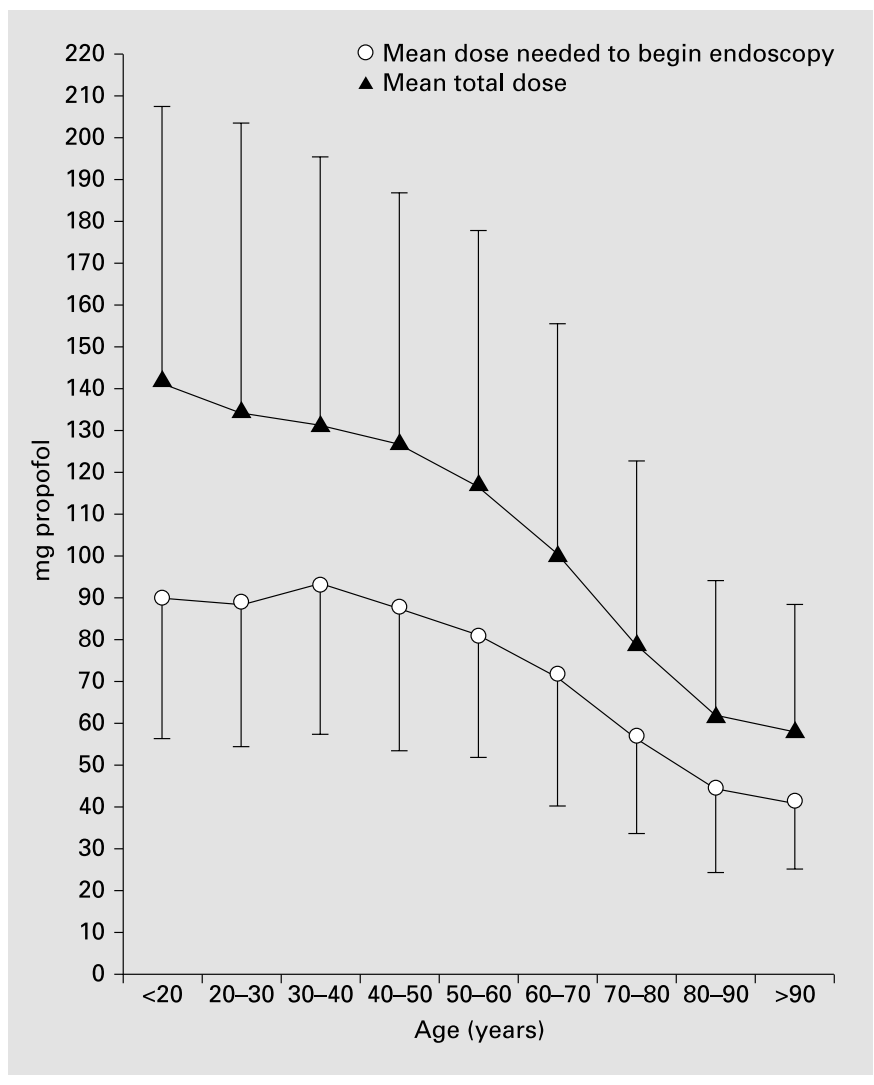

Fig. 1. Influence of age on propofol dose required, based on a prospective evaluation of 4,079 EGDs [according to 31]. Mean and SD.

Table 2. Continuum of sedation depth based on guidelines published by the American Society of Anesthesiologists Task Force on Sedation and Analgesia by Non-Anesthesiologists [34]

\begin{tabular}{|c|c|c|c|c|}
\hline & $\begin{array}{l}\text { Minimal } \\
\text { sedation } \\
\text { (anxiolysis) }\end{array}$ & $\begin{array}{l}\text { Moderate } \\
\text { sedation/analgesia } \\
\text { (conscious sedation) }\end{array}$ & $\begin{array}{l}\text { Deep } \\
\text { sedation/analgesia }\end{array}$ & $\begin{array}{l}\text { General } \\
\text { anesthesia }\end{array}$ \\
\hline Responsiveness & $\begin{array}{l}\text { normal response } \\
\text { to verbal } \\
\text { stimulation }\end{array}$ & $\begin{array}{l}\text { purposeful }{ }^{1} \text { response } \\
\text { to verbal or tactile } \\
\text { stimulation }\end{array}$ & $\begin{array}{l}\text { purposeful }^{1} \text { response } \\
\text { after repeated or } \\
\text { painful stimulation }\end{array}$ & \multirow{4}{*}{$\begin{array}{l}\text { unarousable, even } \\
\text { with painful } \\
\text { stimulus } \\
\text { intervention } \\
\text { often required } \\
\text { frequently } \\
\text { inadequate } \\
\text { may be impaired }\end{array}$} \\
\hline Airway & unaffected & $\begin{array}{l}\text { no intervention } \\
\text { required }\end{array}$ & $\begin{array}{l}\text { intervention may } \\
\text { be required }\end{array}$ & \\
\hline Spontaneous ventilation & unaffected & adequate & may be inadequate & \\
\hline Cardiovascular function & unaffected & usually maintained & usually maintained & \\
\hline
\end{tabular}

1 Reflex withdrawal from painful stimulus is not considered a purposeful response. 
patients might unintentionally slip into a state of deep sedation - or even anesthesia - with concomitant impairment of spontaneous ventilation. In contrast to benzodiazepines, no reversal agent, such as flumazenil (Anexate ${ }^{\circledR}$ ), is available, and patient resuscitation must be carried out using the jaw thrust maneuver, positioning of a nasopharyngeal tube or even positive pressure bag ventilation. Due to the short duration of action, this intervention is fortunately required for only a few minutes. Nevertheless, endoscopists must be aware of this potential danger and alert for any prolonged period of apnea [35]. This risk necessitates that those who administer propofol must have training in advanced cardiac life support (ACLS) and airway management. Indeed, in some countries, propofol's use is restricted solely to the anesthesiologist [9].

One rarely-cited benefit regarding propofol's safety is that the major negative effects of the drug develop concurrently with when the most attention is being focused on the patient. Therefore, any alterations in physiologic parameters can be detected immediately. This stands in contrast to benzodiazepines where active metabolites may have their largest effect after cessation of the endoscopic procedure [36].

\section{Safety Compared to Midazolam}

Three large prospective studies (involving 562 patients) compared propofol to midazolam (or midazolam in combination with meperidine) and found comparable levels of safety $[16,17,37]$. With regard to patient and/or endoscopist satisfaction, various studies have found propofol to be superior [16-18, 38]. However, it must be stated that the drug was not always used in the same fashion, thereby requiring a stratification of propofol use under different circumstances.

\section{Drug Combinations}

Anesthesiologists have proposed regimens in which propofol is combined with an analgesic and/or another sedative [24]. Due to the mentioned lack of analgesic properties, the combination with a pain-relieving drug is rational. Nevertheless, non-anesthesiologists should be extremely cautious of possible side effects since the drugs act synergistically and may cause a depression in ventilation [39]. A combination of propofol with an opioid always necessitates a reduction in the dosage [32]. A longacting opioid (such as pethidine) can be administered in advance [32], but ideally, the profile of action of the administered drug should be comparable and not abolish the benefits of propofol. From this point of view, the com- bination with a very short-acting (and highly potent) opioid, such as alfentanil, for example in a fixed ratio, would make sense for painful procedures [40].

The combination of propofol with a benzodiazepine has been primarily used to ensure deep sedation [41-43] or to reduce the required quantities of the rather expensive propofol [44]. Besides the problem of predicting possible side effects, this schedule obviously eliminates the essential advantage of propofol and therefore presents no improved benefit. The argument that, with benzodiazepines, at least one component should be capable of being neutralized in cases of emergency leads, in our opinion, to a false sense of security. The main thrust should be to prevent an emergency situation by cautious use as well as careful selection and monitoring of the patients.

\section{When Should Propofol Be Used in GI Endoscopy?}

Within the past few years, two different strategies have been developed for using propofol in GI endoscopy. First, by emphasizing its origin as an anesthetic agent and its potential to easily achieve deep sedation, some authors have suggested reserving propofol for prolonged and difficult endoscopic procedures, i.e. using the drug primarily for its superior hypnotic potency [17, 18, 45]. Using this strategy, propofol becomes a second-line drug that can replace the need for having an anesthesiologist, and is reserved for difficult procedures. This enables gastroenterologists to perform endoscopic interventions while patients are in a quiet state of (deep) sedation.

Underscoring its pharmacokinetic properties, other authors have introduced the substance as a routine firstline hypnotic for all EGD and colonoscopies, providing special benefits in an outpatient setting [22, 37, 46, 47]. With this view, its rapid re-awakening and metabolism are major benefits for the physician who strives for a level of sedation comparable to the benzodiazepines.

We employ propofol in the latter fashion as a routine substance for all types of endoscopic procedures, including painful rectoscopies and even liver biopsies.

\section{$E G D$}

For EGDs performed in outpatients, propofol may be the ideal substance [37, 48, 49], although the dosage needed to smoothly perform upper endoscopy may be slightly higher than for colonoscopies with an accompanying increased risk of apnea $[9,20]$. Nevertheless, the short procedure time corresponds very well to the action of the drug. After an adequate level of sedation has been reached, propofol permits most EGDs to be performed without further incremental application of the drug while 
still achieving a perfect amnesia. Patients are able to communicate immediately after the procedure and can be discharged after $20 \mathrm{~min}$, although they should not be allowed to drive.

\section{Colonoscopies}

During colonoscopies, the level of sedation can be adjusted to the patient's need with a deeper level during passage of the sigmoid and a lower level during withdrawal [9]. As do most authors in these procedures, we likewise administer the drug using a bolus technique according to the specific patient's requirement. If applicable, patientcontrolled sedation (see below) may be an ideal method for this type of procedure [40].

\section{ERCP and EUS}

For prolonged procedures, such as ERCP or EUS, a perfusion technique with an injection pump may be more convenient than the bolus technique $[17,45,50]$. The level of satisfaction cited by both the patient and the investigator are superior with propofol than with midazolam [45]. However, conflicting results have been reported from the scant experiences made to date when using a target-controlled infusion (TCI) technique. The need for a considerable titration time makes it unattractive for short procedures, and a high rate of oversedations in a pilot study is noteworthy [51-53].

\section{Who Should Administer Propofol, How Should It Be Administered, and What Type of Monitoring Is Required?}

Four methods of drug administration have been reported. These include propofol administered by: (1) an anaesthesiologist [45, 54]; (2) another physician (gastroenterologist) [17, 18, 50]; (3) a trained nurse [20, 55, 47], and $(4)$ by the patient himself $[40,56]$. In a recent study, the delivery of propofol by registered nurses has been shown to be more cost-effective than administration by an anaesthesiologist or by an additional physician [18]. It thus appears that the introduction of propofol into GI practice is linked to the documentation of its safety in the hands of non-anesthesiologists [39, 57, 58]. Experiences with nurse-administered propofol sedation, abbreviated NAPS, have been reported from different centers in the US and Europe. Together, the authors have examined more than 20,000 NAPSs that took place at two different institutions: a tertiary university hospital and a hospitalbased private practice $[20,23]$. The overall reported safety of NAPS is well comparable to other methods. In more than 50,000 sedations, there has been no observed mortal- ity, no need of endotracheal intubation and the incidence of brief mask ventilation was between 1:500 and 1:1,000 $[9,19,20,23,31,32,47,55,59]$.

\section{Patient-Controlled Sedation (PCS)}

The combination of propofol with an anesthetic agent has likewise been repeatedly shown as practical for PCS $[40,54,56,60,61]$. The typical self-administered bolus consists of $4.8 \mathrm{mg}$ propofol and $125 \mu \mathrm{g}$ alfentanil [40, 56]. All studies showed a perfect safety result with this form of application and a high degree of patient satisfaction. However, part of the concept of PCS is that patients have to react to an unpleasant sensation. Therefore, they often seem to be sedated only at a rather low level and may experience pain more often than do conventionally sedated patients. Although this method seems to provide an individually tailored and adequate sedation that would save on additional personnel resources, this technique may not be applicable in a significant portion of patients who are less than eager to take responsibility for their own sedation.

\section{Monitoring}

Several guidelines have defined the use of sedative drugs by non-anesthesiologists [34, 62-65]. As with any form of conscious sedation, pulse oximetry, nasal oxygen administration and repeated blood pressure measurement are mandatory. With the introduction of propofol, capnography has been suggested as an improved modality for monitoring respiratory activity and for detecting apnea at an earlier stage [35]. Nevertheless, end-tidal $\mathrm{CO}_{2}$ measurement in respired air may provide inaccurate results, and transcutaneous $\mathrm{CO}_{2}$ monitoring has therefore recently been proposed as an alternative for supervising ventilation [66].

\section{Training}

The crucial point in the debate over nurse-administered propofol sedation remains the specific knowledge and training requirements. It is generally claimed that every person involved in NAPS, nurses as well as endoscopists, should have experience and knowledge of both the theoretic basics of monitoring and pharmacology of the drugs used. In addition, they should be trained in practical ACLS procedures, including positive pressure ventilation with a bag valve system $[9,20,33]$. As NAPS is still in its beginnings, the introduction of NAPS should be embedded in a quality assurance program with defined protocols of drug administration and monitoring of the patients' reactions. In agreement with others, we would 
emphasize the need of learning the practical administration of propofol with the support of an anaesthesiologist [9].

\section{Conclusion}

Propofol is a very promising substance that provides remarkable advantages over benzodiazepines for sedation in endoscopy. With its rapid onset and short duration of action, various drug administration methods, including patient-controlled sedation, are practical. The safety profile is almost equal to that of the benzodiazepines and satisfaction reported by both the patient and endoscopist is much higher [33]. The large number of sedations carried out by registered endoscopy nurses confirm that this is also a safe form of application when cautious protocols are used and the nurses are adequately trained.

\section{References}

1 Sorbi D, Gostout CJ, Henry J, Lindor KD Unsedated small-caliber esophagogastroduodenoscopy (EGD) versus conventional EGD: A comparative study. Gastroenterology 1999; 117:1301-1307.

2 Shaker R: A wake-up call? Unsedated versus conventional esophagogastroduodenoscopy. Gastroenterology 1999;117:1492-1495.

3 al Atrakchi HA: Upper gastrointestinal endoscopy without sedation: A prospective study of 2,000 examinations. Gastrointest Endosc 1989;35:79-81.

4 Gasparovic S, Rustemovic N, Opacic M, Bates M, Petrovecki M: Comparison of colonoscopies performed under sedation with propofol or with midazolam or without sedation. Acta Med Austriaca 2003;30:13-16.

5 Rey JF: Sedation for upper gastrointestinal endoscopy: As much as possible, or without? Endoscopy 1996;28:308-309.

6 Adachi W, Yazawa K, Owa M, Koide N, Hanazaki K, Kajikawa S, Kobayashi S, Amano J: Quantification of cardiac stress during EGD without sedation. Gastrointest Endosc 2002; 55:58-64.

7 Yazawa K, Adachi W, Owa M, Koide N, Hanazaki K, Kajikawa S, Kobayashi S, Amano J: Can sedation reduce the cardiac stress during gastrointestinal endoscopy? A study with noninvasive automated cardiac flow measurement by color Doppler echocardiography. Scand J Gastroenterol 2002;37:602-607.

8 Rex DK, Imperiale TF, Portish V: Patients willing to try colonoscopy without sedation: Associated clinical factors and results of a randomized controlled trial. Gastrointest Endosc 1999;49:554-559.

9 Rex DK, Overley C, Walker J: Registered nurse-administered propofol sedation for upper endoscopy and colonoscopy: Why? When? How? Rev Gastroenterol Disord 2003;3:70_ 80.

10 Cheng L, Wiener-Kronish JP: Preprocedure evaluation for sedation and analgesia; in Gropper MA, Wiener-Kronish JP (eds): Conscious Sedation. Philadelphia, Hanley \& Belfus, 2002
11 Lazzaroni M, Bianchi-Porro G: Premedication, preparation, and surveillance. Endoscopy 1999;31:2-8.

12 Froehlich F, Gonvers JJ, Fried M: Conscious sedation, clinically relevant complications and monitoring of endoscopy: Results of a nationwide survey in Switzerland. Endoscopy 1994; 26:231-234.

13 Quine MA, Bell GD, McCloy RF, Charlton JE, Devlin HB, Hopkins A: Prospective audit of upper gastrointestinal endoscopy in two regions of England: Safety, staffing, and sedation methods. Gut 1995;36:462-467.

14 Bah A, Saraga E, Armstrong D, Vouillamoz D, Dorta G, Duroux P, Weber B, Froehlich F, Blum AL, Schnegg JF: Endoscopic features of Helicobacter pylori-related gastritis. Endoscopy 1995;27:593-596.

15 Nelson DB, Barkun AN, Block KP, Burdick JS, Ginsberg GG, Greenwald DA, Kelsey PB, Nakao NL, Slivka A, Smith P, Vakil N: Propofol use during gastrointestinal endoscopy. Gastrointest Endosc 2001;53:876-879.

16 Koshy G, Nair S, Norkus EP, Hertan HI, Pitchumoni CS: Propofol versus midazolam and meperidine for conscious sedation in GI endoscopy. Am J Gastroenterol 2000;95:14761479.

17 Wehrmann T, Kokabpick S, Lembcke B, Caspary WF, Seifert H: Efficacy and safety of intravenous propofol sedation during routine ERCP: A prospective, controlled study. Gastrointest Endosc 1999;49:677-683.

18 Vargo JJ, Zuccaro G Jr, Dumot JA, Shermock KM, Morrow JB, Conwell DL, Trolli PA, Maurer WG: Gastroenterologist-administered propofol versus meperidine and midazolam for advanced upper endoscopy: A prospective, randomized trial. Gastroenterology 2002;123: $8-16$.

19 Clarke AC, Chiragakis L, Hillman LC, Kaye GL: Sedation for endoscopy: The safe use of propofol by general practitioner sedationists. Med J Aust 2002;176:158-161.
20 Heuss LT, Schnieper P, Drewe J, Pflimlin E, Beglinger C: Risk stratification and safe administration of propofol by registered nurses supervised by the gastroenterologist: A prospective observational study of more than 2,000 cases. Gastrointest Endosc 2003;57:664-671.

21 Elitsur Y, Blankenship P, Lawrence Z: Propofol sedation for endoscopic procedures in children. Endoscopy 2000;32:788-791.

22 Dubois A, Balatoni E, Peeters JP, Baudoux M: Use of propofol for sedation during gastrointestinal endoscopies. Anaesthesia 1988;43(suppl): 75-80.

23 Külling D, Rothenbühler R, Inauen W: Safety of non-anaesthesist sedation with propofol for outpatient colonoscopy and esophagogastroduodenoscopy. Endoscopy 2003;358:679-682.

24 White PF: Propofol; in White PF (ed): Textbook of Intravenous Anesthesia. Baltimore, Williams \& Wilkins, 1997, pp 111-152.

25 Niemann C, Gropper MA: Pharmacology of conscious sedation; in Gropper MA, WienerKronish JP (eds): Conscious Sedation. Philadelphia, Hanley \& Belfus, 2002, pp 1-16.

26 Gray PA, Park GR, Cockshott ID, Douglas EJ, Shuker B, Simons PJ: Propofol metabolism in man during the anhepatic and reperfusion phases of liver transplantation. Xenobiotica 1992;22:105-114.

27 Ganapathy S, Herrick IA, Gelb AW, Kirkby J: Propofol patient-controlled sedation during hip or knee arthroplasty in elderly patients. Can J Anaesth 1997;44:385-389.

28 Dell RG, Cloote AH: Patient-controlled sedation during transvaginal oocyte retrieval: An assessment of patient acceptance of patientcontrolled sedation using a mixture of propofol and alfentanil. Eur J Anaesthesiol 1998;15: 210-215.

29 Gilbertson LI: Conscious sedation in special settings. Int Anesthesiol Clin 1999;37:123129.

30 Hammas B, Hvarfner A, Thorn SE, Wattwil M: Propofol sedation and gastric emptying in volunteers. Acta Anaesthesiol Scand 1998;42: 102-105.

31 Heuss LT, Schnieper P, Drewe J, Pflimlin E, Beglinger $\mathrm{C}$ : Conscious sedation with propofol in elderly patients: A prospective evaluation. Aliment Pharmacol Ther 2003;17:1493-1501. 
32 Heuss LT, Schnieper P, Drewe J, Pflimlin E, Beglinger C: Safety of propofol for conscious sedation during endoscopic procedures in high risk patients: A prospective, controlled study. Am J Gastroenterol 2003;98:1751-1757.

33 Sipe BW, Rex DK, Latinovich D, Overley C, Kinser K, Bratcher L, Kareken D: Propofol versus midazolam/meperidine for outpatient colonoscopy: Administration by nurses supervised by endoscopists. Gastrointest Endosc 2002;55:815-825.

34 Practice guidelines for sedation and analgesia by non-anesthesiologists. Anesthesiology 2002; 96:1004-1017.

35 Vargo JJ, Zuccaro G Jr, Dumot JA, Conwell DL, Morrow JB, Shay SS: Automated graphic assessment of respiratory activity is superior to pulse oximetry and visual assessment for the detection of early respiratory depression during therapeutic upper endoscopy. Gastrointest Endosc 2002;55:826-831.

36 Iber FL, Sutberry M, Gupta R, Kruss D: Evaluation of complications during and after conscious sedation for endoscopy using pulse oximetry. Gastrointest Endosc 1993;39:620-625.

37 Carlsson U, Grattidge P: Sedation for upper gastrointestinal endoscopy: A comparative study of propofol and midazolam. Endoscopy 1995;27:240-243.

38 Hofmann C, Kiesslich R, Brackertz A, Jung M: Propofol for sedation in gastroscopy: A randomized comparison with midazolam. Z Gastroenterol 1999;37:589-595.

39 Bell GD, Charlton JE: Colonoscopy - is sedation necessary and is there any role for intravenous propofol? Endoscopy 2000;32:264-267.

40 Külling D, Fantin AC, Biro P, Bauerfeind P, Fried M: Safer colonoscopy with patient-controlled analgesia and sedation with propofol and alfentanil. Gastrointest Endosc 2001;54:17.

41 Cordruwisch W, Doroschko M, Wurbs D: Deep sedation in gastrointestinal endoscopic interventions: Safety and reliability of a combination of midazolam and propofol. Dtsch Med Wochenschr 2000;125:619-622.

42 Schmitt T, Seifert H, Dietrich CF, Caspary WE, Wehrmann T: Propofol sedation in endoscopic manometry of Oddi's sphincter. Z Gastroenterol 1999;37:219-227.

43 D'Honneur G, Rimaniol JM, el Sayed A, Lambert Y, Duvaldestin P: Midazolam/propofol but not propofol alone reversibly depress the swallowing reflex. Acta Anaesthesiol Scand 1994;38:244-247.
44 Reimann FM, Samson U, Derad I, Fuchs M, Schiefer B, Stange EF: Synergistic sedation with low-dose midazolam and propofol for colonoscopies. Endoscopy 2000;32:239-244.

45 Jung M, Hofmann C, Kiesslich R, Brackertz A: Improved sedation in diagnostic and therapeutic ERCP: Propofol is an alternative to midazolam. Endoscopy 2000;32:233-238.

46 Patterson KW, Casey PB, Murray JP, O’Boyle $\mathrm{CA}$, Cunningham AJ: Propofol sedation for outpatient upper gastrointestinal endoscopy: Comparison with midazolam. Br J Anaesth 1991;67:108-111.

47 Walker JA, McIntyre RD, Schleinitz PF, Jacobson KN, Haulk AA, Adesman P, Tolleson S, Parent R, Donnelly R, Rex DK: Nurseadministered propofol sedation without anesthesia specialists in 9,152 endoscopic cases in an ambulatory surgery center. Am J Gastroenterol 2003;98:1744-1750.

48 Borgeat A, Wilder-Smith O: Propofol sedation for outpatient upper gastrointestinal endoscopy. Br J Anaesth 1992;68:116.

49 Chin NM, Tai HY, Chin MK: Intravenous sedation for upper gastrointestinal endoscopy: Midazolam versus propofol. Singapore Med J 1992;33:478-480.

50 Vargo JJ, Zuccaro G Jr, Dumot JA, Shay SS, Conwell DL, Morrow JB: Gastroenterologistadministered propofol for therapeutic upper endoscopy with graphic assessment of respiratory activity: A case series. Gastrointest Endosc 2000;52:250-255.

51 Gillham MJ, Hutchinson RC, Carter R, Kenny GN: Patient-maintained sedation for ERCP with a target-controlled infusion of propofol: A pilot study. Gastrointest Endosc 2001;54:1417.

52 Kazama T, Takeuchi K, Ikeda K, Ikeda T, Kikura M, Iida T, Suzuki S, Hanai H, Sato S: Optimal propofol plasma concentration during upper gastrointestinal endoscopy in young, middle-aged, and elderly patients. Anesthesiology 2000;93:662-669.

53 Church JA, Stanton PD, Kenny GN, Anderson JR: Propofol for sedation during endoscopy: Assessment of a computer-controlled infusion system. Gastrointest Endosc 1991;37:175179.

54 Roseveare C, Seavell C, Patel P, Criswell J, Kimble J, Jones C, Shepherd H: Patient-controlled sedation and analgesia, using propofol and alfentanil, during colonoscopy: A prospective randomized controlled trial. Endoscopy 1998;30:768-773.
55 Rex DK, Overley C, Kinser K, Coates M, Lee A, Goodwine BW, Strahl E, Lemler S, Sipe B, Rahmani E, Helper D: Safety of propofol administered by registered nurses with gastroenterologist supervision in 2000 endoscopic cases. Am J Gastroenterol 2002;97:11591163.

56 Lee DW, Chan AC, Sze TS, Ko CW, Poon CM, Chan KC, Sin KS, Chung SC: Patient-controlled sedation versus intravenous sedation for colonoscopy in elderly patients: A prospective randomized controlled trial. Gastrointest Endosc 2002;56:629-632.

57 Graber RG: Propofol in the endoscopy suite: An anesthesiologist's perspective. Gastrointest Endosc 1999;49:803-806.

58 Byrne MF, Baillie J: Propofol for conscious sedation? Gastroenterology 2002;123:373375.

59 Heuss LT, Schnieper P, Pflimlin E, Beglinger $C$ : Nurse-administered sedation with propofol under observation of the endoscopist: A prospective observation study with more than 5,000 patients. Gastrointest Endosc 2003;57: AB105.

60 Ng JM, Kong CF, Nyam D: Patient-controlled sedation with propofol for colonoscopy. Gastrointest Endosc 2001;54:8-13.

61 Heiman DR, Tolliver BA, Weis FR, O'Brien BL, DiPalma JA: Patient-controlled anesthesia for colonoscopy using propofol: Results of a pilot study. South Med J 1998;91:560-564.

62 Guidelines for training in patient monitoring and sedation and analgesia. American Society for Gastrointestinal Endoscopy. Gastrointest Endosc 1998;48:669-671.

63 Fleischer D: Monitoring the patient receiving conscious sedation for gastrointestinal endoscopy: Issues and guidelines. Gastrointest Endosc 1989;35:262-266.

64 Faigel DO, Baron TH, Goldstein JL, Hirota WK, Jacobson BC, Johanson JF, Leighton JA, Mallery JS, Peterson KA, Waring JP, Fanelli RD, Wheeler-Harbaugh J: Guidelines for the use of deep sedation and anesthesia for GI endoscopy. Gastrointest Endosc 2002;56:613617.

65 SGNA guidelines for nursing care of the patient receiving sedation and analgesia in the gastrointestinal endoscopy setting. Gastroenterol Nurs 2000;23:125-129.

66 Heuss LT, Schnieper P, Hayoz J, Tschupp A, Beglinger $\mathrm{C}$ : Patient surveillance with a new combined transcutaneous pulse oximetry and carbon dioxide tension single ear sensor during colonoscopies: A pilot study. Gastrointest Endosc 2003;57:AB78. 